Int. J. Electrochem. Sci., 15 (2020) $1669-1680$

\title{
Anodic Stripping Determination of Selenium in Seawater Using an Electrode Modified with Gold Nanodendrites/Perforated Reduced Graphene Oxide
}

\author{
Hong Wei ${ }^{1,2}$,Dawei Pan ${ }^{1,2, *}$, Yuanding Cui ${ }^{3}$,Haiying Liu ${ }^{3}$, Guangheng Gao ${ }^{4}$, Jianjun Xia ${ }^{5, *}$ \\ ${ }^{1}$ Key Laboratory of Coastal Environmental Processes and Ecological Remediation, Yantai Institute of \\ Coastal Zone Research, Chinese Academy of Sciences, Yantai 264003, P.R. China. \\ ${ }^{2}$ University of Chinese Academy of Sciences, Beijing 100049, P.R. China \\ ${ }^{3}$ Electromechanical Engineering Institute, Jiangxi Application Engineering Vocational College, \\ Pingxiang 337042, P.R. China \\ ${ }^{4}$ Biology Institute, Qilu University of Technology (Shandong Academy of Sciences), Key Laboratory \\ for Biosensors of Shandong Province, Jinan 250353, P.R. China \\ ${ }^{5}$ Research and Development of Center, China Tobacco Yunnan Industrial Co., Ltd., Kunming 650231, \\ P.R. China. \\ *E-mail: dwpan@yic.ac.cn , lordxia@126.com
}

doi: $10.20964 / 2020.02 .51$

Received: 24 October 2019 / Accepted: 4 December 2019 / Published: 31 December 2019

\begin{abstract}
Anodic stripping voltammetric determination of selenium was successfully and effectively performed using an electrode modified with gold nanodendrites/perforated reduced graphene oxide (AuNDs/PrGO), which was synthesized via a facile electrochemical deposition route. The compositions of the AuNDs/P-rGO were characterized by Scanning electron microscopy. The experimental parameters of the Se(IV) accumulation, Se(IV) potential, the gold deposition time and the interference by other ions were discussed in detail. The linear range of selenium at the AuNDs/P-rGO modified electrode was from $3 \mathrm{nM}$ to $300 \mathrm{nM}$, with a detection limit of $0.9 \mathrm{nM}$ under optimized conditions. The proposed electrode showed satisfactory results in both real seawater samples and standard artificial seawater samples with different salinities.
\end{abstract}

Keywords: Electrochemical deposition; square wave voltammetry; Se(IV); seawater; spiked seawater sample

\section{$\underline{\text { FULL TEXT }}$}

(C) 2020 The Authors. Published by ESG (www.electrochemsci.org). This article is an open access article distributed under the terms and conditions of the Creative Commons Attribution license (http://creativecommons.org/licenses/by/4.0/). 